\title{
How can countries create outbreak response policies that are sensitive to maternal health?
}

\author{
Ensuring women's need for sexual and reproductive healthcare are met should be a priority during \\ disease outbreaks, say Maira L S Takemoto and colleagues
}

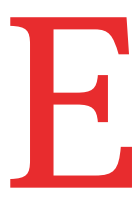

pidemics and pandemics can have a serious effect on maternal health and healthcare, with dire outcomes for women, newborns, and their families. ${ }^{1}$ Covid-19 is no exception. Covid-19 has direct clinical consequences for maternal health, including preterm births, maternal deaths, and near misses. ${ }^{2}$ The indirect effects of reduced access to antenatal care and assisted birth, resulting from the requirement for lockdown and social distancing, also risk increasing all cause maternal mortality, stillbirth, and neonatal mortality. ${ }^{3-5}$ Public health interventions to contain covid-19 were expected to have less effect on people's lives than not doing anything, which might have led to a collapsed health system incapable of providing care.

To mitigate the effect of the outbreak, policies are needed that are sensitive to maternal health. Using experience from Ebola, Zika, and covid-19, we outline some strategies that can ensure continuity of maternal care during crises, examining supply, demand, and structural challenges.

\section{Supply side challenges to service provision}

Governments responding to outbreaks of highly infectious disease face difficult decisions about resource allocation. Human resources, medical supplies, bed availability, and funding are often reallocated to maximise care during the health emergency. During Ebola, Zika, and now covid-19, we have seen cuts to preventive

\section{KEY MESSAGES}

- Maternal health services have been hindered by the response to the health emergency, with consequences for pregnant women and children

- Lessons from Ebola, Zika, and covid19 can highlight policies which minimise the impact on this group of women

- Efforts should be made to incorporate such approaches into pandemic preparedness and responses care, tests, and antenatal and postnatal visits that are usually routine, or a switch to alternative forms of care, such as online or phone appointments for pregnancies perceived as low risk. ${ }^{367}$ In India, health centres were even forced to turn away women in labour owing to redistribution of staff, shortage of beds, and health workers' fears of disease transmission due to limited personal protective equipment. ${ }^{8}$

Such changes to routine provision of maternity services have led to increased rates of stillbirth and maternal mortality. ${ }^{3-5}$ For example, modelling data suggest that there might be an additional 56000 maternal deaths over six months in Nepal because of a 10\% decrease in service provision, and over one million additional child deaths. ${ }^{9}$

Alterations to maternity services are amplified by workforce shortages resulting from relocation of staff to crisis wards, or sick leave, or death. ${ }^{10}$ Data from Mexico indicate that five months after the country's first instance of covid-19, over 11000 healthcare workers had been infected, 1000 admitted to hospital, and 200 with severe disease. ${ }^{11}$ In the United Kingdom it is estimated that 49000 National Health Service staff were sick with covid-19 or forced to self-isolate during a one week period in January $2021 .^{12}$ The combination of these factors might also affect the capacity of health services to provide good quality care, and the user's perception of care. Poor infection control caused by low stocks of personal protective equipment and insufficient training during the 201820 Ebola outbreak in the Democratic Republic of Congo might have resulted in patients who accessed maternity services being infected with Ebola. Such experiences increased the public perception of health clinics as a source of infection. ${ }^{13}$

During the Ebola and Zika epidemics, many women and their partners considered it was not the right time to have a baby. ${ }^{13}$ Disruptions to the supply chain, limitations on clinic access, and restrictions on public mobility meant it was not always possible to obtain contraception to prevent pregnancy, or broader sexual and reproductive healthcare. These difficulties are particularly important as unintended pregnancies, unsafe abortion, and untreated sexually transmitted infections are likely to increase during such health crises, with higher rates of gender based violence, transactional sex, and more adolescent girls being out of school. Despite the direct effects on adolescent girls and women's short and longer term physical and mental health, response to the epidemic does not include routine maintenance of maternal healthcare services. In some instances, these services might be curtailed where abortion rights are limited. ${ }^{14}$

Some new efforts have been made to ensure access to sexual and reproductive healthcare during covid-19, such as the free provision of contraceptives in pharmacies and supermarkets in France, Italy, and Spain. In other countries community health workers have delivered contraceptives to reduce visits to health facilities. ${ }^{15}$ In the UK, government policy was changed to allow telemedicine service to deliver early medical abortion care so that clients could take abortion pills in their own homes. Similar strategies were adopted in France. ${ }^{16}$

Since the onset of the covid-19 pandemic, the World Health Organization has insisted that the provision of good quality maternal and sexual and reproductive healthcare services is essential and has produced guidance on how to safely adapt and deliver services during this time. ${ }^{17}$ This guidance, however, depends on a high level of covid19 testing capacity and personal protective equipment, which many countries cannot reliably offer, and a more skilled workforce than many low and middle income countries have in place. Despite these challenges, different interventions have been used in some low and middle income countries to ensure continuity of services, such as setting up triage spaces to screen for covid-19, prioritising maternity care workers for personal protective equipment training, adapting antenatal visits to maintain social distancing, and 
setting up maternity wards in covid-19 treatment centres in refugee camps. ${ }^{15}$ Many of these interventions were put in place early on, learning from large scale Ebola outbreaks, but have never featured in pandemic preparedness plans, and were not universal. All countries can learn from these experiences to ensure that pandemic plans continue to include maternal and sexual and reproductive healthcare.

\section{Demand-side limitations to use of maternity services}

These supply-side challenges compound changes in the way in which women use maternity care. During 2020 women in Nepal stopped or delayed using a facility to give birth, which seems to have resulted in an increased rate of stillbirth. ${ }^{5}$ A similar pattern was seen in Sierra Leone during the 2014-16 Ebola outbreak. ${ }^{1819}$ For women to receive appropriate healthcare during disease outbreaks, they must want to access such care, and feel that they can do so without unnecessary barriers. During the Ebola outbreak in the Democratic Republic of Congo, pregnant women feared that arriving at a health centre with a symptom of disease might result in their isolation in a treatment centre without appropriate obstetric care. ${ }^{13}$ Similar fears have been reported during the covid-19 pandemic. Restrictions placed on the participation of birth partners during antenatal services and labour have also left many women feeling intensely vulnerable. ${ }^{20}$ Policies to separate women with covid-19 from their newborn babies might also have led some women to avoid health facilities. ${ }^{2122}$

Innovative and community centred approaches have been used to drive demand for maternity care. Such efforts include moving antenatal care to unused spaces such as schools to reduce women's concerns about catching covid-19 from a "contaminated" space. For example, in the Netherlands, where women have the right to choose where they give birth, midwife teams have identified unused hotels as potential alternative birth settings. ${ }^{23}$ Similarly, the network of midwifery units in the UK recommended the creation of birthing centres close to hospitals. ${ }^{24}$

Learning from Ebola and to respond to a decrease in availability of basic services, innovative approaches to the delivery of maternal healthcare have helped to ensure continuity of care and deal with demandside constraints. In the Democratic Republic of Congo, building on efforts during the Ebola outbreak, midwives, with the support of United Nations Population
Fund, organised mobile health clinics to continue providing midwifery care to pregnant women during lockdown of Kinshasa. ${ }^{25}$ The Nurses and Midwives Association of Southern Sudan used teleconsultation, and radio to provide health education on covid-19, midwifery care, and case referrals to pregnant women. ${ }^{26}$ Another lesson from Ebola is that it is essential for health workers to make daily visits to pregnant women who are self-isolating owing to covid-19, so that if labour or pregnancy complications occur women can be transferred early to a covid19 secure maternity unit. Other changes in community level services have included training community providers, such as traditional birth attendants, in prevention and control of covid-19 infection-an important approach to reducing harm. ${ }^{15}$

\section{Structural barriers to continuity of care}

Structural barriers might also decrease demand for maternal healthcare during disease outbreaks. ${ }^{27}$ When health service provision moves online, access to care by populations with limited telephone or internet connection, or who have disabilities or language constraints, can be disproportionately affected..$^{1328}$ Lockdown measures used to curb disease transmission also have a substantial impact on household earnings. Many people, and particularly women, have experienced disruptions to work or lost their job owing to business closures and inability to work from home. This situation is even more acute for workers in the informal economy, leaving many people unable to afford healthcare. Evidence from some low and middle income settings has shown that in out-of-pocket healthcare systems, women are less likely to contact services. ${ }^{29}$ Given the effect of covid-19 on women's economic security, we expect this additional financial pressure to further impede women's use of maternal health services. Other structural constraints include changes to transport systems, such as cuts to public transport because of restrictions on mobility, or increased costs, ${ }^{29}$ and the additional domestic childcare responsibilities placed on women and girls as a consequence of lockdown.

Policies that help to minimise structural barriers to maternal healthcare include food distribution, and emergency income assurance programmes, as implemented in Brazil during covid-19. ${ }^{30}$ Other countries have offered "laissez-passer" for pregnant women to travel to health services during lockdown. ${ }^{15}$ Moreover, provision of free healthcare during Ebola in the Democratic Republic of Congo was largely successful in encouraging patients to seek care. Despite this, many still chose to pay for private healthcare because free government-run health facilities often had Ebola screening posts at their entrances. Many people preferred to use facilities without such screening, as they feared being screened as Ebola positive (based on symptoms common to many illnesses) and transported to an Ebola centre for testing. ${ }^{13}$ Similar findings were reported in Belize when pregnant women chose not to get tested for Zika, despite free screening during 2016-17, as travel costs to test centres remained high, and given a strict regulatory environment for abortion, few trajectories were available to women who tested positive. ${ }^{31}$ Such social protection strategies, although temporary and insufficient to compensate for income losses and ensure adequate living conditions during a pandemic, can help to reduce structural barriers to maternal healthcare among vulnerable populations.

\section{Conclusion}

Pregnancy and childbirth will continue to occur during infectious disease emergencies, despite, as in the case of Zika and covid-19, government requests for women to delay pregnancy. ${ }^{32}$ Thus strategies must be put in place to ensure good quality maternal health services can still be provided to everyone who needs them. Delays in receiving adequate reproductive healthcare are considered key determinants of preventable maternal and perinatal adverse outcomes, particularly in low resource settings and within low resilience health systems. A reduction in this service deprioritises women and their needs. Difficult trade-offs must be made during an emergency, but a mother's life must not be perceived as less valuable than that of someone infected with a pathogenic virus. In addition to the moral argument, maternal morbidity and mortality have long term negative consequences for families and communities, including their effect on the health and survival of newborns and children, financial loss, and disruption of education for older children who have to care for younger siblings.

The Ebola, Zika, and covid-19 outbreaks have made abundantly clear that policies in response to the outbreak, sensitive to maternal health are not being developed alongside the pandemic preparedness process. We believe this can be rectified by including experts in maternal health 
in emergency planning. Rapid and transparent monitoring of efforts will also help to identify barriers to maternal healthcare during a crisis and inform remedial action. Maternal health sensitive policies and efforts, such as the strategies outlined here, must be put in place now, for future waves of covid-19, to ensure that good quality maternity care is not damaged in times of crisis.

Contributors and sources: MLST has carried out research into the effect of covid-19 on maternal and perinatal outcomes in Brazil, particularly how access to healthcare, and social determinants of health, affect such outcomes. GM has operational and research experience in the outbreaks of Ebola in 2013-16, west Africa and in 2018-20, North Kivu Democratic Republic of Congo; she is particularly interested in how reproductive health services are affected by epidemics. MA has worked as an obstetrician during Zika and covid-19 in Brazil and leads a research study on covid-19 in pregnancy. CNG has carried out research into barriers to the use of maternal and child health services, specifically the prevention of mother-to-child transmission. Currently, she is studying the impact of covid-19 on the use of maternal and child health services in the Democratic Republic of Congo. AFT has carried out research into community engagement and effect on maternal health of Ebola in Sierra Leone. CW has carried out research into the different effects of epidemics on men and women, including the Zika outbreak and currently coleads two research projects into gender and covid- 19 .

Competing interests: We have read and understood BMJ policy on declaration of interests and have no relevant interests to declare.

Provenance and peer review:Commissioned; externally peer reviewed.

This article is part of a series commissioned by The $B M J$, based on an idea from the United Nations University-International Institute for Global Health and the World Health Organization, to mark the 25th anniversary of the adoption of the 1995 Beijing Declaration and platform for action. Open access fees were paid by the UN University-International Institute for Global Health. The BMJ retained full editorial control over external peer review, editing, and decision to publish. The views expressed are those of the authors and do not necessarily represent the views, decisions or policies of UNU, UNU-IIGH, or WHO.

Maira L S Takemoto, postdoctoral researcher ${ }^{1}$ Gillian McKay, doctor of public health candidate ${ }^{2}$ Melania Amorim, professor of gynaecology and obstetrics $^{3}$

Cady N Gbomosa, PhD candidate ${ }^{4}$

Angus F Tengbeh, PhD candidate ${ }^{5}$

Clare Wenham, assistant professor of global health policy ${ }^{6}$

${ }^{1}$ Universidade Estadual Paulista Júlio de Mesquita Filho, Botucatu, SP, Brazil

${ }^{2}$ London School of Hygiene and Tropical Medicine, Faculty of Public Health and Policy, London, UK ${ }^{3}$ Instituto de Medicina Integral Professor Fernando Figueira, Recife, Brazil

${ }^{4}$ University of Ottawa Faculty of Health Sciences, Ottawa, Ontario, Canada

${ }^{5}$ Institute for Global Health and Development, Queen Margaret University, School of Health Sciences, Edinburgh, UK
'London School of Economics and Political Science, London, UK

Correspondence to: CWenham

C.Wenham@lse.ac.uk

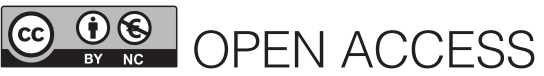

This is an Open Access article distributed under the terms of the Creative Commons Attribution IGO License (https://creativecommons.org/licenses/ by-nc/3.0/igo/), which permits use, distribution, and reproduction for non-commercial purposes in any medium, provided the original work is properly cited.

\section{Check for updates}

1 Sochas L, Channon AA, Nam S. Counting indirect crisis-related deaths in the context of a low-resilience health system: the case of maternal and neonatal health during the Ebola epidemic in Sierra Leone. Health Policy Plan 2017;32(suppl_3):iii32-9. doi:10.1093/heapol/czx108

2 Menezes MO, Takemoto MLS, Nakamura-Pereira M, et al, Brazilian Group of Studies for COVID-19, Pregnancy. Risk factors for adverse outcomes among pregnant and postpartum women with acute respiratory distress syndrome due to COVID-19 in Brazil. Int J Gynaecol Obstet 2020;151:415-23. doi:10.1002/ijgo.13407

3 Sarwer A, Javed B, Soto EB, Mashwani ZU. Impact of the COVID-19 pandemic on maternal health services in Pakistan. Int J Health Plann Manage 2020;35:1306-10. doi:10.1002/hpm.3048

4 Lumbreras-Marquez MI, Campos-Zamora M, Seifert SM, et al. Excess maternal deaths associated with coronavirus disease 2019 (COVID-19) in Mexico. Obstet Gynecol 2020;136:1114-6. doi:10.1097/ AOG.0000000000004140

5 Kc A, Gurung R, Kinney MV, et al. Effect of the COVID-19 pandemic response on intrapartum care, stillbirth, and neonatal mortality outcomes in Nepal: a prospective observational study. Lancet Glob Health 2020;8:e127381. doi:10.1016/S2214-109X(20)30345-4

6 Renfrew MJ, Cheyne H, Craig J, et al. Sustaining quality midwifery care in a pandemic and beyond. Midwifery 2020;88:102759. doi:10.1016/j. midw.2020.102759

7 Yerger P, Jalloh M, Coltart CEM, King C. Barriers to maternal health services during the Ebola outbreak in three West African countries: a literature review. BMJ Glob Health 2020;5:e002974. doi:10.1136/ bmjgh-2020-002974

8 Gettleman J, Raj S. 8 Hospitals in 15 hours: a pregnant woman's crisis in coronavirus pandemic in Delhi. The Times of India 2020 June 24. https:// timesofindia.indiatimes.com/blogs/foreign-media/8hospitals-in-15-hours-a-pregnant-womans-crisis-inthe-pandemic/

9 Roberton T, Carter ED, Chou VB, et al. Early estimates of the indirect effects of the COVID-19 pandemic on maternal and child mortality in low-income and middle-income countries: a modelling study. Lancet Glob Health 2020;8:e901-8. doi:10.1016/S2214109X(20)30229-1

10 Bar-Zeev S, Breen-Kamkong C, Ten Hoope-Bender P, Sahbani S, Abdullah M. UNFPA supporting midwives at the heart of the COVID-19 response. Women Birth 2021;34:4-6.

11 Antonio-Villa NE, Bello-Chavolla OY, Vargas-Vázquez A, Fermín-Martínez CA, Márquez-Salinas A, BahenaLópez JP. Health-care workers with COVID-19 living in Mexico City: clinical characterization and related outcomes. Clin Infect Dis 2020;ciaa1487. doi:10.1093/cid/ciaa1487

12 Woods R. Tens of thousands of UK National Health Service workers fall ill with COVID-19. World Socialist Web Site. 2021 Jan 15. https://www.wsws.org/en/ articles/2021/01/16/nhsw-j16.html
13 Mckay G. Not all that bleeds is Ebola: how the DRC outbreak impacts reproductive health. International Rescue Committee, 2019. https://www.rescue-uk. org/report/not-all-bleeds-ebola-how-drc-outbreakimpacts-reproductive-health

14 Wenham C, Arevalo A, Coast E, et al. Zika, abortion and health emergencies: a review of contemporary debates. Global Health 2019;15:49. doi:10.1186/ s12992-019-0489-3

15 READY Initiative. Ready: global readiness for major disease outbreak response: maternal, newborn, and reproductive health and covid-19: adaptations, successes, challenges, and next steps. an expert consultation. USAID, 2020. https://www.readyinitiative.org/wp-content/uploads/2020/12/MNRHand-COVID-19-Consultation-Report-2020.pdf

16 Gibelin K, Agostini A, Marcot M, Piclet H, Bretelle F, Miquel L. COVID-19 impact in abortions' practice, a regional French evaluation. / Gynecol Obstet Hum Reprod 2021;50:102038. doi:10.1016/j. jogoh.2020.102038

17 World Health Organization. Maintaining essential health services: operational guidance for the COVID-19 context interim guidance. WHO, 2020 https://reliefweb.int/sites/reliefweb.int/files/ resources/WHO-2019-nCoV-essential_health services-2020.2-eng.pdf

18 Iones SA, Gopalakrishnan S, Ameh CA, White S, van den Broek NR. 'Women and babies are dying but not of Ebola': the effect of the Ebola virus epidemic on the availability, uptake and outcomes of maternal and newborn health services in Sierra Leone. BMJ Glob Health 2016;1:e000065. doi:10.1136/ bmjgh-2016-000065

19 Jones S, Sam B, Bull F, et al. 'Even when you are afraid, you stay': provision of maternity care during the Ebola virus epidemic: a qualitative study. Midwifery 2017;52:19-26. doi:10.1016/j. midw.2017.05.009

20 Black B, Laking J, McKay G. Birth partners are not a luxury. BMJ Opinion, 2020. https://blogs.bmj.com/ bmj/2020/09/24/birth-partners-are-not-a-luxury/

21 Suzumori N, Goto S, Sugiura-Ogasawara M. Management strategy of pregnant women during COVID-19 pandemic. Aust N ZJ Obstet Gynaecol 2020;60:E9-10. doi:10.1111/ajo.13202

22 Walker KF, O’Donoghue K, Grace N, et al. Maternal transmission of SARS-COV-2 to the neonate, and possible routes for such transmission: a systematic review and critical analysis. BJOG 2020;127:132436. doi:10.1111/1471-0528.16362

23 Summers H. NHS urged to turn hotels into birth centres during crisis. The Guardian 2020 April 1. https://www.theguardian.com/society/2020/ apr/01/nhs-urged-to-turn-hotels-into-birth-centresduring-coronavirus-crisis

24 Summers $\mathrm{H}$. NHS urged to turn hotels into birth centres during crisis. The Guardian 2020 Apr 1. https://www.theguardian.com/society/2020/ apr/01/nhs-urged-to-turn-hotels-into-birth-centresduring-coronavirus-crisis

25 UNFPA. Democratic Republic of the Congo: Mobile clinics reach women hiding in fear. UNFPA, 2019. https://www.unfpa.org/resources/democratic-republic congo-mobile-clinics-reach-women-hiding-fear

26 Government of Canada. Midwives save lives through thick and thin. 2020. https://www.international. gc.ca/world-monde/stories-histoires/2020/ midewives_save_lives_sages_femmes_sauvent vies.aspx?lang=eng

27 Amnesty International. The devastating effects of COVID-19 on maternal health in Zimbabwe. 2020. https://www.amnesty.org/en/latest/ campaigns/2020/04/the-devastating-effects-ofcovid19-on-maternal-health-in-zimbabwe/

28 Jardine J, Relph S, Magee LA, et al. Maternity services in the UK during the coronavirus disease 2019 pandemic: a national survey of modifications to standard care. BIOG 2021:128:880-9. doi:10.1111/1471-0528.16547. 
29 Ahmed SAKS, Ajisola M, Azeem K, et al, Improving health in slums collaborative. Impact of the societal response to COVID-19 on access to healthcare for non-COVID-19 health issues in slum communities of Bangladesh, Kenya, Nigeria and Pakistan: results of pre-COVID and COVID-19 lockdown stakeholder engagements. BMJ Glob Health 2020; 5:e003042. doi:10.1136/bmjgh-2020-003042
30 Gurgel ADM, Santos CCSD, Alves KPS, Araujo JM, Leal VS. Government strategies to ensure the human right to adequate and healthy food facing the Covid-19 pandemic in Brazil. Cien Saude Colet 2020;25:4945-56. doi:10.1590/1413 812320202512.33912020

31 Gray D, Mishtal J. Managing an epidemic: Zika interventions and community responses in Belize.
Glob Public Health 2019:14:9-22. doi:10.1080/174 41692.2018.1471146

32 Roa M. Zika virus outbreak: reproductive health and rights in Latin America. Lancet 2016;387:843. doi:10.1016/S0140-6736(16)00331-7

Cite this as: BMJ 2021;373:n1271

http://dx.doi.org/10.1136/bmj.n1271 